\title{
BARTOMEU DE TRESBENS, FÍSIC I ASTRÒLEG DEL REI PERE EL CERIMONIÓS I L'INFANT JOAN: ENTRE EL SERVEI A LA CORONA I AL MUNICIPI
}

\author{
Carmel Ferragud \\ Institut d'Història de la Medicina i de la Ciència López Piñero. Universitat de València \\ carmel.ferragud@uv.es \\ ORCID iD: https://orcid.org/0000-0002-9756-9257
}

Recibido: 4 marzo 2017; Aprobado: 1 septiembre 2017.

Cómo citar este artículo/Citation: Ferragud, Carmel (2018), “Bartomeu de Tresbens, físic i astròleg del Rei Pere el Ceremoniós i I'infant Joan: entre el servei a la corona i al municipi”, Asclepio, 70 (2): p227. https://doi.org/10.3989/asclepio.2018.11

RESUM: Bartomeu de Tresbens fou un metge, astròleg i filòsof al servei de dos reis de la Corona d’Aragó, Pere IV el Cerimoniós i el seu fill, el duc Joan, futur Joan I el Caçador, entre els anys 1360 i 1375, aproximadament. La seua important obra de contingut astrològic a penes ha estat estudiada, si n'exceptuem el Llibre de les nativitats. De la mateixa manera, la major part de la seua biografia ens és desconeguda. Conservem documents, correspondència fonamentalment, de la seua relació amb la monarquia, però també altres registres que el relacionen amb els municipis de Barcelona i Cervera. Molt particularment, en aquest segon cas, Tresbens va estar temptat per les autoritats municipals per fer de metge i possiblement de mestre. Aquest estudi fa un repàs a la seua biografia però se centra particularment en les negociacions del metge amb Cervera. Una estratègia amb la qual Tresbens sembla que volia assegurar un lloc on passar la resta dels seus dies i amb un sou desmesurat.

PARAULES CLAU: astrologia; medicina medieval; contracte; casa reial; Corona d’Aragó.

\section{BARTOMEU DE TRESBENS, PHYSICIAN AND ASTROLOGER IN THE SERVICE OF KING PETER THE CERE- MONIOUS AND THE INFANT JOHN: BETWEEN THE SERVICE TO THE CROWN AND THE MUNICIPALITY}

ABSTRACT: Bartomeu de Tresbens was a physician, astrologer and philosopher at the service of two kings of the Crown of Aragon, Peter IV the Ceremonious and his son, Duke John, the future John I the Hunter, between 1360 and 1375, approximately. His major work of astrological content has hardly been studied, except for the Llibre de les nativitats (Book of Nativities). Similarly, most of his biography is not known. The documents, which are mainly the correspondence of its relationship with the monarchy, are preserved, but also other records that connect him to the municipalities of Barcelona and Cervera. Particularly in the latter case, Tresbens was tempted by the municipal authorities for being the physician and possibly teacher of the town. This study gives an overview of his biography but it focuses particularly on the negotiations of the doctor with Cervera, in the context of the local medical and health care. This was a strategy which seems Tresbens wanted to make to find a place to spend the rest of his days with an excessive salary.

KEY WORDS: astrology; medieval medicine; contract; royal household; Crown of Aragon. 
El 19 d'agost de 1926 es publicà en el diari de València Las Provincias un article titulat "El Mestre en Medeçina En Bertomeu de Tresbens". Formava part d'una secció anomenada "Página retrospectiva". El breu article, el signava Joaquín Tuixans (Joaquim Tuixans $\mathrm{i}$ Pedragosa). L'autor era un metge i historiador, oriünd de Badalona, nascut el 1882, que va exercir la seua professió mèdica a Vila-real fins a la seua mort (Pujol i Ros, 2012, p. 21-23). Tuixans alternà la tasca clínica amb l'escriptura de treballs pròpiament de recerca en medicina en general, i particularment de topografies mèdiques, però també de treballs d'arqueologia i d'història. La figura del metge erudit, interessat per la història i la cultura valenciana en general, identificada també per extensió amb tota la catalana com a passat comú dins l'antiga Corona d'Aragó, no era gens estranya en les darreres dècades del segle XIX i principi del $X X$. Efectivament, enmig del moviment cultural conegut com la Renaixença, un grup de metges volgueren utilitzar la història de la medicina per reinvindicar-se com a professionals i reivindicar també els orígens de la pàtria, la seua cultura i la seua llengua (Ferragud i López Terrada, 2017). En aquest sentit, l'inici de l'article de Tuixans dedicat a Tresbens és eloqüent:

“Els qui sentim sincerament la tradiçió medique valentina i llurs títols esplendents, que admiren les gestes positives dels nostres avantspassats, doctors sapientíssims, els professen agrahiment i pregona reconeixença, puig ennoblint lo llinatge medic valençiá ens ennoblim, i dignificantlo els dignifiquen... Y yo que voldrie que estes quartilles foren penyore de gratitud vers en Bertomeu Tresbens...".

En realitat, Tuixans transcrivia en l'article tres documents procedents de l'Arxiu de la Corona d'Aragó (ACA). Ara bé, la transcripció del primer d'ells (ACA, C, reg. 1811 , f. 59v; 10-12-1374) a penes s'ajusta al document original. Interessa ací remarcar que l'autor va introduir pel seu compte, entre altres continguts, la frase: Dirigitur magistro valentino Bartholomeo de tribus bonis. La impostura, però, li valgué per fer aquesta lectura inflamada i jocfloralesca de la figura de Tresbens. No era la primera vegada que Tuixans s'atrevia a fer afirmacions força arriscades en els seus treballs. Aquell mateix any de 1926 va publicar a Vila-real un estudi on va confegir un arbre genealògic d'Arnau de Vilanova, que el convertia en membre d'una il.lustre nissaga provençal (Tuixans, 1926). Joaquim Carreras Artau i Miquel Batllori s'encarregaren de desmuntar tota aquella hipotètica geneaologia (Carreras Artau i Batllori, 1947, p. 20-21). Del que no tenim constància és que Tuixans haguera treballat en un buidatge sistemàtic de documents procedents de l'Arxiu de la Co- rona d'Aragó, com per trobar les tres peces singulars sobre Tresbens que va "editar". Cal recordar que, pocs anys abans, el 1921, Rubió i Lluch havia exhumat els primers documents sobre l'il.lustre metge astròleg en la seua magnífica col·lecció diplomàtica, sense donar notícia d'aquells (Rubió i Lluch, 1908-1921, vol. I, p. 250, i vol. II, p. 131-132 i 175). Però també és ben cert que els historiadors catalans, valencians i mallorquins de l'època intercanviaven força material d'arxiu que empraven en els seus treballs, i que possiblement fou aquesta la via per la qual li varen arribar.

En qualsevol cas, Tuixans va saber assenyalar la importància de la figura de Tresbens apel-lant al Llibre de les nativitats, "tractant d'Astrologia i medicina espajirista", del qual es conservava un manuscrit a París $^{1}$ i també un altre al monestir de Montserrat, ara a la Biblioteca Lambert Mata. ${ }^{2}$ Efectivament, Bartomeu de Tresbens (fl. 1359-1375) fou un físic i astròleg que va estar al servei del rei Pere el Cerimoniós i del seu fill, el duc Joan, futur Joan I el Caçador. Així, va dedicar un conjunt d'obres d'astrologia en català al rei Pere: Llibre de les nativitats, Tractat de les interrogacions, Tractat de les eleccions i Libel d'investigacions de tresors. ${ }^{3}$ Tanmateix només el primer ha estat editat amb l'inapropiat títol de Tractat d'astrologia (Tresbens, 1957-1958; Chabàs, 2004, p. 483-514; Cifuentes, 2006, p. 209; Ryan, 2011, p. 111-112). Com ha remarcat Sebastià Giralt, l'autor que ha dedicat l'estudi més aprofundit a la figura i l'obra de Tresbens, ell mateix es va definir clarament com a metge del rei, "en la part de phísica" i en astrologia i "expert de philosofia", així com a "pobre letrat e humil sercador e servidor de veritat dels térmens de philosophia, de medecina e de astrologia" (Giralt, 2017a).

Amb tot, si bé Tresbens ja va suscitar interès fa temps entre els estudiosos de la medicina i de l'astrologia, ha estat molt recentment que el conjunt de la seua producció astrològica i la seua biografia han pogut estudiar-se amb major profunditat. Ara bé, sobre la trajectòria biogràfica del personatge encara hi ha notables mancances. ${ }^{4}$ Si bé Sebastià Giralt n'ha elaborat la biografia més completa, convé aprofundir en els detalls que ens proporcionen aquests documents. Ací, a banda d'ampliar els detalls biogràfics, pretenem endinsar-nos en un episodi de particular interès: I'intent per esdevenir metge contractat pel municipi de Cervera.

\section{AL SERVEI DEL MUNICIPI I DE LA CORONA}

No sabem res dels orígens familiars de Bartomeu de Tresbens, ni quan va nàixer ni on. La primera notícia documental que tenim del nostre personatge, quan 
encara no sembla tenir relació amb la família reial, és del 22 de març de 1359. Aquella data, juntament amb els físics barcelonins Ramon de Tesarac, Pere Ros d'Orsins i Arnau Germà, procediren a examinar Jaume de Pallars dels seus coneixements de medicina. ${ }^{5}$ 'acord amb el capítol de les corts de Montsó de 1289 del rei Alfons II el Liberal, aquell que volguera exercir la medicina havia de ser examinat en presència dels prohoms del lloc per físics competents. Llavors, cinc consellers de la ciutat de Barcelona s'havien reunit a casa del notari Simó de Rovira, escrivà del Consell, també davant tres mercaders, els físics esmentats i tres cirurgians barcelonins (Francesc de Mas, Bernat Camós i Pere Andreu), els quals hi feien de testimonis, i el lloctinent del veguer, Nicolau de Rovira, en absència d'aquell. Els metges li feren moltes preguntes per tal de conèixer si era competent en l'art de física. Finalment, manifestaren que era apte per desenvolupar totes les tasques pròpies d'un metge i es demanà que el notari n'expedira el certificat corresponent.

En realitat, no era habitual que un examen d'aquelles característiques implicara tantes persones. ${ }^{6}$ Però, és ben cert que els examinadors triats eren alguns dels físics universitaris, mestres en arts i en medicina, més conspicus de la Barcelona de la segona meitat del segle XIV. Que Tresbens formara part d'aquella nòmina ens indica a la clara que ja tenia una consideració i estatus que el situaven en l'elit dels practicants de la medicina. Amb tot, mereix que fem algunes consideracions respecte als perfils d'aquests físics. Efectivament, com veurem, Tresbens està més pròxim a l'itinerari professional i vital de Pere Ros, que no al d'Arnau Germà o Ramon de Tesarac. Els dos primers tingueren una vinculació molt estreta amb la casa reial i viatjaren constantment requerits pel rei. Els altres dos estaven instal.lats a la ciutat de Barcelona, per bé que ocasionalment treballaren per a la casa reial.

Així, pel que fa a Arnau Germà podem donar compte de la seua presència en la cort i els beneficis reportats. Al juliol de 1362 va rebre 900 sous per haver atès el rei; al maig de 1363 percebia 80 sous per atendre els infants de diverses malalties; i el 1368 cobrà 10 florins per haver atès de nou el rei, amb altres dos físics. ${ }^{7}$ Tot just aquell any, Germà va ser eximit d'impostos pels consellers de Barcelona, en atenció al temps que havia estat vivint i treballant per a la ciutat. I sabem també de diverses pensions que cobrava de la mateixa ciutat (Ferragud, 2005, p. 331-332, 342). La condició perquè es mantingueren aquests privilegis seria que continuara residint a Barcelona. No deixa de ser simptomàtic que la relació amb la casa reial es tallara fins al 1385, quan de nou tornà a atendre el rei. De fet, durant aquest any i el següent, al final de la vida de Pere el Cerimoniós, serví el rei en diverses ocasions. El 24 de setembre de 1385 se li concedien 350 florins per haver tingut cura d'una malaltia del rei juntament amb Bernat Oriol. ${ }^{8}$

Pel que fa a Ramon de Tesarac, es tractava d'un metge assalariat per la ciutat, que igualment cobrava algunes pensions censals. ${ }^{9}$ Tant ell com Arnau Germà pertanyien a la classe mitjana alta de la societat, i devien gaudir d'una fortuna considerable, per bé que les notícies que en tenim no són abundants. ${ }^{10}$

Dels quatre físics esmentats, és Pere Ros d'Orsins el més conegut i estudiat (Comenge, 1901, p. 151157; Ferragud, 2005, p. 694 (índex); Cifuentes, 1995, p. 224-225). Aquest doctor en medicina, que era "professor en medicina" i "metge major de Casa del senyor Rey", era descendent d'un cavaller romà que acompanyà Jaume I en les conquestes de Mallorca i València. Els anys 1343 i 1344, Pere Ros va participar en l'expedició a Mallorca i en les campanyes al Rosselló. Durant els any crítics de 1347 i 1348, en plena revolta i guerra de les Unions i el daltabaix de la pesta negra, va romandre al costat del rei. Tot aquest servei li va ser recompensat a bastament amb gran quantitat de prebendes i emoluments. Fou també examinador per encàrrec del rei i acabà ennoblit per mercè de la monarquia.

El nostre metge astròleg té un perfil similar al d'aquests tres metges. Entre 1360 i 1375, Tresbens va mantenir una estreta vinculació amb la família reial, amb un parèntesi documental entre 1364 i 1369. En efecte, els documents demostren la seua posició oficial de físic i astròleg reial. El veiem exercint aquestes funcions no solament per a Pere el Cerimoniós sinó també per al seu primogènit, el duc Joan, i la seua primera esposa Mata d'Armanyac, amb nombrosos desplaçament pels diversos regnes de la Corona d'Aragó, sovint pels requeriments dels seus patrons.

Podem suggerir com a hipòtesi que Tresbens entrà al servei del rei Pere vers el 1360, ja que tot just fou per aquell temps que comencem a tenir constància continuada de l'interès del monarca per l'astrologia. De fet, el més antic dels documents que vinculen Tresbens amb la Corona ja sembla tenir-hi relació, i això ha fet pensar que ja actuava com a astròleg abans d'esdevenir metge reial. El servei a la Corona li hauria servit per promocionar-se professionalment i per convertir-se en un astròleg expert gràcies al contacte amb el cercle d'astrònoms/astròlegs que treballaven per a la reialesa. Fet 
i fet, els astròlegs de l'època baixmedieval solien exercir també de físics reials. Amb tot, la doble dedicació de Tresbens sembla independent l'una de l'altra, atès que no s'observa cap orientació mèdica en la seua obra astrològica, sinó que més aviat aquesta es relacionava amb les necessitats del poder (Giralt, 2017b).

El 15 de maig de 1360, el rei Pere va requerir des d'Alagón al justícia d'Aragó, Johan López de Sessé, que obligara a estar a la total disposició de Tresbens els ferrers de Saragossa que ell necessitara per a una obra que havia de fer. No sabem a què es referia, però és versemblant pensar que estava relacionat amb algun instrument astronòmic. ${ }^{11}$ Els anys següents, diversos documents el situen al regne d'Aragó. Sebastià Giralt ha posat de manifest que hi ha una molt clara relació entre els desplaçaments del rei recollits en la Crònica durant la seua campanya aragonesa en la guerra contra la Corona de Castella i les estades de Tresbens en aquestes poblacions aragoneses (Giralt, 2017a). Així mateix, consta que va posseir propietats derivades d'una herència a Pina de Ebro, prop de Saragossa, per les quals va pledejar (1369-1370), amb la intercessió, fins i tot, de l'infant Joan. ${ }^{12}$

El 1372 sabem que era a Barcelona. A mitjan any, la trajectòria de Tresbens podria haver canviat si s'haguera materialitzat un contracte amb la vila de Cervera, aspecte sobre el qual ens detindrem en detall més endavant. Tanmateix, les negociacions no arribaren a bon port. Tresbens continuà amb el seu servei habitual a la casa reial. Així, l'1 de setembre de 1373, quan encara era a Barcelona, el duc Joan va escriure des de València al seu pare per suplicar-li que li enviara Tresbens amb urgència, sense que se n'especifique el motiu. ${ }^{13}$ Encara més, el dia 4 hi insistia amb una segona carta a Tresbens, en la qual li recordava la primera i li demanava que el vinguera a trobar a València amb uns llibres d'astrologia i de medicina que necessitava. ${ }^{14}$ Un albarà del 27 de setembre confirma que l'astròleg, finalment, hi va acudir des de Barcelona. ${ }^{15}$

Al cap d'un any, l'octubre de 1374, Tresbens tornava a ser al regne de València al costat de l'infant Joan. En una carta datada el 23 d'octubre de 1374, el duc li donà llicència per traure del regne 150 quintars de figues (uns $6.200 \mathrm{~kg}$ ). ${ }^{16}$ La circulació interna i externa d'aquesta fruita solia ser lliure, excepte en determinades conjuntures, com ara durant les guerres, quan se'n limitava l'exportació, ja que eren aliments amb alt valor energètic que podien substituir la mancança d'altres. I el període 1374-1375, tot just quan se li concedeix el privilegi a Tresbens, amb la pau amb Castella encara sense signar, fou especialment difícil perquè es va viure un temps de grans caresties de blat.
El Cerimoniós va permetre llavors una gran mobilitat de figues en direcció a les grans ciutats on la manca d'aliments bàsics era alarmant. L'any 1374 havia estat un període especialment fructífer per a la collita de figues al sud del regne de València, i aquesta fruita esdevingué la moneda de canvi per vendre-la fora a canvi d'obtenir blat i introduir-lo als territoris de la Corona (Ferrer i Mallol, 2001, p. 886-888 i 905-906).

El document ens aporta diverses dades d'interès. Una, que Tresbens tingué presència i relació amb tres regnes de la Corona d'Aragó i amb les majors ciutats; en segon Iloc, la dedicació a afers mercantils; i en tercer lloc, el favor reial permanent als seus diversos afers privats. Tanmateix, aquesta no era la primera ocasió en què Tresbens havia mostrat els seus interessos mercantils i s'havia aprofitat de la intercessió de la monarquia. El 1372, l'astròleg havia rebut un salconduit del rei per comerciar amb els seus socis Guillem i Joan Duran, pare i fill, de Pàmias (comtat de Foix). ${ }^{17}$

Més endavant, el 31 d'octubre de 1374, des de Sant Mateu, el duc escrivia al rei per pregar-li que rebera Tresbens per escoltar possiblement unes prediccions astrològiques sobre el monarca, l'hereu i els regnes de la Corona d’Aragó. Així mateix, li demanava que, després d'escoltar-lo, li enviara resposta mitjançant el mateix Tresbens. ${ }^{18}$ És possible que hi haja una relació entre aquesta petició i una altra del rei; per una lletra datada el 2 de desembre de 1374, Pere fa anar Tresbens a Cervera, on es troba el monarca, per certs "afers nostres" que ha de portar a terme en col-laboració amb Dalmau Sesplanes, astrònom-astròleg també al servei reial, un dels autors de les famoses Taules de Barcelona. ${ }^{19}$

Talment com s'esdevé amb els serveis astrològics, trobem notícies relatives a l'assistència mèdica prestada per Tresbens a la casa reial. L'esposa de l'infant, Mata d'Armanyac, demanà al rei en una carta datada el 10 de desembre de 1374 a Lleida, que li enviara Tresbens perquè es trobava refredada $\mathrm{i}$ amb febre. ${ }^{20}$ Però molt clarament indica la seua influència el fet que el 12 d'abril de 1375 el duc Joan, per indicació de Tresbens, manara que tots els homes i les dones, "de la llei i condició" que foren, que practicaven la medicina o la cirurgia en tots els regnes de la Corona, a excepció de professors o llicenciats universitaris, foren sotmesos a un examen rigorós i suficient. ${ }^{21}$

Els dos últims documents coneguts sobre Tresbens són del 28 d’abril de 1375. Després, el seu rastre es perd i, per tant, cal pensar que molt probablement va morir poc ${ }^{22}$ després. 


\section{UN CANVI DE RUMB}

El 1372, Bartomeu de Tresbens va ser temptat de donar un canvi a la seua vida i esdevenir metge, i potser també mestre d'escola, de Cervera, després de rebre una oferta dels paers i del Consell municipal. Eren temps en què, en moltes ciutats i viles, ambdós elements, l'educació dels infants i l'assistència als malalts, havien esdevingut indispensables. Eren dos objectius que les autoritats tenien en ment; irrenunciables en aquell darrer quart de segle XIV per a un municipi amb una economia puixant com era Cervera (Turull, 1990, p. 355-360). ${ }^{23}$ Efectivament, a la baixa edat mitjana, Cervera, cap d'una vegueria i del comtat erigit per Pere el Cerimoniós per al seu hereu, havia esdevingut progressivament el centre demogràfic $i$ econòmic d'una regió caracteritzada per la presència de nombroses petites senyories. La seua població estava integrada fonamentalment per una massa de pagesos que explotaven terres on conreus comercials com el raïm i el safrà tenien gran rellevància. Encara més, entre 1360 i 1379 Cervera tenia també una important població susceptible de necessitar una escola, atesa la seua ocupació: un total de 299 individus, entre els quals cal destacar un important nombre que es dedicaven al tèxtil i a la pell (83) i al comerç (46), a banda dels 29 que es dedicaven a la sanitat i els 56 notaris i juristes (Turull, 1989, p. 371-372). Però cal insistir-hi, la terra i els seus productes eren el centre entorn del qual giraven les principals activitats, i fins i tot els artesans i els practicants de la medicina no renunciaven a posar en explotació terres per obtenir l'autoabastiment $\mathrm{i}$ uns diners en el mercat, com ara amb la producció i venda de safrà (Turull, 1992, p. 65-96). Així, per exemple, el 1375 l'infant Joan es va adreçar al veguer de Cervera per la denúncia contra l'apotecari Jaume de Berga, que havia envaït les terres del difunt Pere Tallada i les havia sembrat, amb el consegüent perjudici per als seus hereus. ${ }^{24}$

Fet i fet, Cervera no semblava una mala opció per instal·lar-s'hi, i, tanmateix, la contractació de Tresbens mai no es va produir, malgrat els esforços de les autoritats municipals per aconseguir els seus serveis. ${ }^{25}$ En el present apartat analitzem les circumstàncies de la negociació entre les autoritats municipals i el metge astròleg, el context en què es varen produir i què va propiciar la manca d'entesa entre les parts.

\section{Practicants de la medicina i situació assistencial a Cervera}

Entre les diverses possibilitats que tenia un metge d'aconseguir un salari, una bona opció era la contracta- ció amb un municipi. Per una quantitat estable, per bé que de vegades molt moderada, si tenim en compte el que es podia cobrar en ocasions per un únic tractament mèdic, ${ }^{26}$ a més també d'algun benefici fiscal i d'altres guanys més que es podien anar sumant, un practicant de la medicina podia obligar-se a residir per un període determinat -que normalment no excedia els cinc anys- per tal d'atendre els veïns d'un municipi, a vegades amb l'acord explícit de no cobrar-los. Aquestes fórmules contractuals eren una realitat en molts indrets, grans i petits, d'arreu la Corona d'Aragó, des de la darreria del segle XIII. ${ }^{27}$ Moguts per la por a epidèmies que havien sentit que començaven a arribar a terres veïnes, o bé simplement perquè feia temps que no disposaven dels serveis d'un professional mèdic que ara els veïns els sol-licitaven, el ben cert és que podem trobar tant en el món urbà com en el rural les més diverses pràctiques i modalitats de contractació.

Cervera, com també altres municipis catalans entre els 3.000 i 5.000 habitants, cas de Manresa o Puigcerdà, eren suficientment grans com per oferir bones oportunitats a metges ambiciosos, però no tan grans com per resultar definitivament atraients per als millors. Molt sovint, captar els individus de major prestigi, sobretot els que s'havien format a la universitat, era bastant complicat, i aquests tendien a moure's incessantment a la recerca de les millors oportunitats (McVaugh, 1993, p. 194). Els municipis mitjans havien vist que, sense una política d'acostament dels metges, aquests recalaven a les ciutats majors, amb més possibilitats de guanys. Per això desenvolupaven les seues pròpies estratègies per trobar practicants de la medicina mitjançant l'enviament de representants del municipi. Aquests negociaven amb els físics i cirurgians les millors condicions possibles quant a l'atenció a demanar, un salari i altres beneficis atraients, però no onerosos, tant com fóra possible, per a la hisenda municipal. No foren, per tant, mers elements passius que esperaren que algun anara a parar fortuïtament a les seues terres. Un fet, aquest darrer, que òbviament també s'esdevingué: com s'ha d'explicar si no la presència d'un metge de Xàtiva, el clergue Lluís Mandoll, mestre en sacra pàgina i en arts i medicina, a Cervera, contractat el 1475? (Duran i Sanpere i Gómez Gabernet, 1944, Apèndix, doc. 50).

Tenim notícia que per aquells anys Cervera disposava de practicants de la medicina, alguns d'ells instal·lats a la vila durant dècades. Era el cas del cirurgià Bernat de Foix, documentat entre 1332 i 1388. Foix va exercir nombrosos càrrecs públics, entre els quals el de paer, en sis ocasions, i el de mostassaf, en una, 
cosa que demostra el seu estatus de prohom (Ferragud, 2005, p. 505). També la vila tenia alguns metges jueus. El 1370, Jafudà del Corral, físic de Cervera, era nomenat metge i familiar de la casa del rei. ${ }^{28}$ Un any després, Bonanasc Alfaquim era un físic de la ciutat que havia estat admès com a metge domèstic del rei, amb tots els privilegis i llibertats, com ara dur armes prohibides, o no haver de dur les marques difamants en el vestit. ${ }^{29}$ Temps després, el 1375, Pere d'Isovals, magister in artibus et in medicina, examinà el també jueu de Cervera Sullam Deuslogar, el qual va ser considerat competent, tot i que tardà quatre anys més a rebre l'oportuna llicència. ${ }^{30}$

Ara bé, que Cervera tingué dificultats per captar metges ho posen de manifest les concessions de Ilicències reials per exercir la medicina a determinades persones, que contravenien la legislació. Així ho féu el fill del Cerimoniós, el futur rei Joan I, quan concedí Ilicència per exercir la medicina a la vila de Cervera al juny de 1364 a l'apotecari Bartolí de Morranyà, qui solia practicar la física i la cirurgia, i que ho feia a més absque extorsione salarii immoderati, privilegi que féu extensible el 1369 per poder exercir la medicina a la resta de la Corona (Solsona i Sorní, 1984, p. 43-48). ${ }^{31}$ Morranyà, en realitat, era un apotecari que abastia la casa reial, i que gaudia del seu favor, com ho mostra el fet que Pere el Cerimoniós, quan el 1361, apel·lant a l'usatge Princeps namque, cridà a la mobilització general i concedí que a Cervera se'n pogueren exceptuar, entre altres, el físic mestre Pere de Rivals, el barber Ramon de Canet i l'apotecari Morranyà, o el que és el mateix, el monarca procurà la permanència d'uns mínims que hi garantiren l'assistència mèdica. Anys després, el 1369, Bartolí i el seu germà reberen el privilegi de dur armes prohibides. ${ }^{32}$ I és que la problemàtica assistencial romania sempre vigent en una població pròspera i amb una evolució demogràfica creixent. També al juliol de 1385, l'infant Joan donà Ilicència per exercir la medicina, malgrat el que deien les ordenances catalanes, a Brunissèn, esposa de l'apotecari cerverí Francesc Oller, de la qual es deia era experta in arte fisice i que havia guarit molts malalts. ${ }^{33}$

No semblava haver-hi problema, però, amb les garanties dels productes relacionats amb l'art de l'apotecaria. La presència d'11 apotecaris ens indica la importància donada al subministrament de medicaments i de tota l'àmplia gamma d'elements que elaboraven i distribuïen els qui es dedicaven a aquesta art (Vela i Aulesa, 2015, p. 127-142). Cal subratllar, fins i tot, el seu pes polític demostrat per la presència en el Consell municipal d'apotecaris com els germans Pere
(1365) i Bartomeu Ripoll (1368) o Jaume de Berga (1368). Aquests nombrosos apotecaris degueren ser un estímul per a un físic, ja que eren garantia de l'expedició de les receptes, i també la possibilitat de bones aliances per obtenir guanys quan s'arribava a bons acords, malgrat les prohibicions vigents. ${ }^{34}$ Però poder disposar d'apotecaris protegits per la casa reial encara degué ser més estimulant per a un altre domèstic del rei com també ho era Tresbens.

Segurament l'exemple dels germans apotecaris Pere i Bartomeu Ripoll encarna de forma molt evident el que podia haver conduït l'astròleg Tresbens a considerar la possibilitat de traslladar-se a Cervera. La documentació de la Cancelleria il·lumina la protecció permanent del rei Pere el Cerimoniós vers aquests dos apotecaris, sense que en cap cas constatem que treballaren directament per abastir de productes la casa reial. En els anys posteriors a la contractació frustrada de Tresbens, els problemes dels Ripoll s'anaven acumulant, després de grans operacions mercantils en què s'havien involucrat, i el Cerimoniós els ajudà a superar el tràngol, no sense alguna complicació. El 1374 , els Ripoll i dos dels seus criats havien estat acusats d'haver-se resistit a un algutzir, però foren absolts pel rei ${ }^{35}$ Dos anys després, el rei va permetre als dos germans i un soci de traure 200 somades de blat (uns $25.000 \mathrm{~kg}$ ) per via marítima per a la seua revenda. ${ }^{36}$ । això no deixa de sorprendre perquè la vila travessava per aquell temps un moment de dificultats en l'abastiment frumentari (Canela i Garayoa, 1986, p. 57 i 59). I encara el 1378 el rei intervindrà quan, davant una execució ordenada contra els béns dels apotecaris, ells hi al-leguen estar en possessió d'un privilegi d'allongament. ${ }^{37}$ L'ambició dels projectes comercials dels Ripoll era molt evident i els alts riscos que havien pres començaven a tornar-se en contra seua. Aquest mateix any, el conseller reial fra Guillem de Guimerà exigia la devolució de 2.000 sous més 600 d'interessos a Bartomeu. Per això, el monarca va ordenar que se li confiscaren béns per un valor suficient per fer front al préstec. ${ }^{38}$ Dies després, Rigot de Nicosa, comanador de la casa de l'hospital de Sant Joan de Jerusalem a Barcelona, manifestava que el deute dels germans Ripoll i de Maria, la seua mare, era de 1.200 florins d'or, que ells rebutjaven de tornar. El rei ordenà al veguer que actuara per reclamar la quantitat als Ripoll. ${ }^{39}$ Mesos després, el rei confirmava una sentència de la batllia de Cervera que ordenava als Ripoll pagar 3.155 sous de Barcelona al mercader Bertran d'Arcs, a qui els devien, més 495 sous de despeses efectuades en el judici. La requisició de béns es va produir, i si fem cas del clam de Brunissèn, l'esposa de Bartomeu, la 
cosa era tan greu que no tenien prou béns per subsistir, i el rei els va concedir disposar d'una part del safrà i d'altres espècies; concessió que no agradà gens el creditor d'Arcs, que protestà iradament. El rei acabarà ordenant que no es requisaren els béns de Brunissèn. ${ }^{40}$ Un any després, el monarca tornava a intervenir en favor seu, i s'adreçava al batlle de Cervera per informar-lo de l'allongament de cinc anys per una quantitat que Bertran d'Arcs els demanava per una comanda. ${ }^{41}$ Les tensions, però, eren massa fortes i Pere i la seua esposa Brunissèn, el seu germà Bartomeu i Maria, la mare, perseguits pels seus creditors de Cervera, es van traslladar a Balaguer. El rei reforçà la seua protecció amb un guiatge de dos anys. Un guiatge del qual no dubtaren a fer-ne abús, ja que es negaren a pagar durant cinc anys el cens de 55 sous anuals que feien a un beneficiat de l'església de Santa Maria de Cervera per una casa que tenien al carrer del Corral. ${ }^{42}$

Si Pere el Cerimoniós i el seu fill tenien una actitud tan condescendent i pròvida amb els practicants de la medicina de Cervera, si els favors eren permanents, si a més les possibilitats de guanys eren tan àmplies, no solament amb la pràctica de la medicina sinó també en el món dels negocis, per què no posar-hi rumb? Fet i fet, Tresbens degué pensar que el favor reial de què ja disposava es perpetuaria en una vila on el rei intervenia permanentment a favor de determinats individus.

\section{L'intent de contractació}

El març de 1371, el batlle de Cervera, en nom dels paers i els prohoms de la vila, va explicar a Pere el Cerimoniós que el físic Pere de Rivals -veí de Cervera de feia 10 anys, com s'ha vist- havia incomplit el seu acord de restar-hi a canvi d'una pensió anual, ja que havia traslladat la seua residència a Puigcerdà, deixant la gent de Cervera sense assistència mèdica (cum in ibi non sit alius fisicus) en un moment de pesta, tot just quan més els feia falta un metge. El rei va ordenar que es respectara l'acord entre el metge i la vila i que aquest fóra obligat a tornar i residir-hi. ${ }^{43}$ Tanmateix, més d'un any després la qüestió no estava resolta. El 24 de maig de 1372, el Consell municipal de Cervera es va reunir amb els paers per tractar el tema de la manca de metge. Com que s'acostava l'estiu i veien que això podria comportar un greu perill per a la salut dels veïns, van pensar a fer-se amb els serveis de Pere d'Isovals, un físic que havia estat ja assalariat més de vint anys abans. Se li oferien cinc anys de contracte a raó de 500 sous anuals, com havia estat habitual, i una exempció d'impostos. El 30 de juliol de 1372, es van reunir de nou les autoritats. Els paers posaren de manifest que a la vila no solament continuaven sen- se cap metge contractat sinó que tampoc no tenien cap mestre que regentara l'escola. Explicaven que un metge nouvingut anomenat Berenguer Sabater havia ofert els seus serveis per un salari anual bastant moderat, de 15 lliures (300 sous), més una exempció d'impostos, però que ells no volien acceptar-lo sense que abans no es pronunciara el Consell.

És ben sabut que, des de mitjan segle XIV, les grans ciutats, però també els nuclis semiurbans més modestos i, fins i tot, les viles rurals de la Corona d'Aragó, disposaven de diferents mecanismes per aconseguir l'alfabetització dels infants (Cruselles, 1997). Els municipis es veieren empesos a la creació d'escoles, on acudien sobretot els fills dels menestrals i mercaders, ben necessitats del coneixement de lletra. Entre els mercaders eren comuns els llibres de comptabilitat, com també als obradors de tot tipus d'oficis. La bona marxa i prosperitat d'aquests negocis passava per un coneixement de la lectura, l'escriptura i l'aritmètica. A aquesta oferta docent, s'hi sumaven els mestres independents, que oferien els seus serveis privats per ensenyar de lletra, però també la música o l'esgrima. Una altra qüestió eren les elits, que tenien els seus propis preceptors. S'integraven així, en definitiva, les terres de la Corona a un model de gran abast que afectà tot l'Occident medieval, amb moltes particularitats segons els casos (Verger, 1999; Black, 2005, p. 18-36). Cervera no va ser una excepció i tenim notícies de l'existència d'una escola almenys des del 1332 (Duran i Sanpere i Gómez Gabernet, 1944; Llobet i Portella, 1999).

Si un tret va caracteritzar moltes escoles arreu de la Corona d'Aragó, com també a altres indrets europeus, fou el recurs a professionals de la medicina per regentar-les i exercir de mestre. De fet, alguns metges manifestaren una especial sensibilitat vers l'educació en fomentar la creació d'una escola amb diners propis (Ferragud, 2005, p. 265-268). I és que la proliferació d'escoles era gran, però el nombre de batxillers i Ilicenciats en el mercat, en canvi, escàs. És per això que l'ensenyament es va constituir en una ocupació més per als metges, una font més d'ingressos complementària a l'exercici de la medicina. De fet, els contractes municipals solien recollir ambdues obligacions: la pràctica de la medicina i l'ensenyament. A Cervera, fins un total de sis mestres de lògica i gramàtica, dels 18 que se'n coneixen per als segles XIV i XV, foren titulats en medicina. Certament, un nucli important de la població, bàsicament l'elit que tenia a les seues mans la major part de la riquesa, no en podia prescindir. Però també és molt possible que els camperols benes- 
tants, i els que no ho eren tant, portaren els seus fills a l'escola. Fet i fet, la institució escolar era ja clau i indispensable per al bon funcionament de la cosa pública.

Els físics havien tingut la necessitat, en el cas de ser formats en estudis generals, d'haver cursat arts, el trivium i el quadrivium, continguts propedèutics per a l'accés a la facultat de medicina. Se'ls exigia l'ensenyament de les regles gramaticals i l'ortografia, però també esdevenien garants de l'educació cívica (Cruselles, 1997, p. 193-199). Tot i que no s'esmenta explícitament, en aquestes escoles degué ser molt important l'estudi de l'aritmètica i particularment el maneig de l'àbac, fonamental per a les comptabilitats (Black, 2004, p. 827-846). Si fem cas dels capítols per a la regència de les escoles cerverines del contracte que l'any 1405 s'establí amb el metge i mestre Bernat Valentí, és de destacar que aquests ensenyants devien tenir un assistent, batxiller, que garantia així la permanent atenció de les escoles en la seua absència. Això era fonamental si tenim en compte que les responsabilitats mèdiques podien obligar a abandonar l'aula en qualsevol moment d'urgència (Benito i Monclús, 1999, p. 217-219).

Doncs bé, en aquella conjuntura de necessitat de metge i mestre per a la vila, els síndics, que eren llavors a Barcelona, havien sabut que en aquell moment Bartomeu de Tresbens era a la capital, i pensaren que si li donaven una pensió suficient segurament aquest s'avindria a oferir els seus serveis als cerverins. Els paers hi apostaren, però, això sí, partint d'una oferta més humil que la que havien gaudit anteriorment els metges de Cervera, xifrada en 10 lliures (200 sous), que es podria augmentar fins a 15 , més l'exempció d'impostos. També acordaren que es negociaria el temps de durada del contracte. Crida l'atenció la rebaixa salarial, segurament relacionada amb el descens demogràfic i el consegüent empobriment de la vila. Cal insistir que la situació aquell estiu era dramàtica. La pesta hi havia fet acte de presència, com ho demostra el fet que el dia de sant Miquel s'haguera fet una processó a la vila per traure's de sobre el mal pestilent (Llobet i Portella, 1983, p. 39). Fins i tot, els síndics que s'havien traslladat a buscar metge havien caigut malalts, i la vila encara oferia exempcions fiscals per als barbers que volgueren fer-hi residència, ja que també n'hi havia escassesa (Canela i Garayoa, 1986, p. 56).

Passats quasi dos mesos, el Consell es va tornar a reunir amb els paers. Aquests manifestaren haver rebut una carta dels seus representants, que eren a Barcelona. En la missiva s'indicava que havien pogut parlar amb Bartomeu, i exposaren les condicions exigides pel metge.
Les peticions eren bastant més elevades del que havien pensat: 50 lliures (1.000 sous) per un període de 15 anys o per a tota la seua vida, una exempció total d'impostos i una casa de franc. Sens dubte, les autoritats degueren quedar espantades ja que les condicions de Tresbens ultrapassaven de molt el que havien estat acostumats a satisfer, i a més el físic reial es volia assegurar un període de contracte inusualment llarg. Realment el devia compensar abandonar la capital per traslladar-se a Cervera i compaginar el servei a la Corona i al municipi. Molt possiblement, malgrat que no s'indique res al respecte, el metge s'hauria reservat el dret a poder cobrar els clients, i cal pensar que el preu que pagava el municipi era un incentiu per lligar-lo i obligar-lo a fer-hi residència. ${ }^{44}$ Pensem, tanmateix, que un madur Tresbens, que aleshores devia tenir més de 50 anys, pogué preparar-se el terreny per acabar els seus dies tranquil-lament en una vila apartada del tràfec de la capital i la presència sovintejada en la cort, si bé Cervera era un dels punts ben comunicats del Principat. No era estrany que els físics reials adoptaren aquesta actitud de retirada a la ruralia en moments de la seua vida, sobretot en l'ocàs, i, si podia ser, com a senyors feudals amb els seus propis vassalls. Així, Jaume d’Avinyó, cirurgià de Pere el Cerimoniós, i amb forta influència a la ciutat de València, era posseïdor d'una alqueria anomenada Vilella, al terme de Sueca, des del 1368 (Ferragud, 2005, p. 404-405). El també físic del Cerimoniós, el gironí Guillem Colteller, acabarà, després d'un procés d'adquisicions i donacions reials, per esdevenir senyor d'Esponellà i del seu castell (Ferragud, 2005, p. 523-525). Gabriel Garcia, metge de la reina Maria, esposa d'Alfons el Magnànim, passà els últims anys de la seua vida retirat a Vinalesa, un petit llogaret al nord de València que havia comprat, on va morir cap al 1461. Afectat de gota, fou requerit per atendre la reina Maria, esposa d'Alfons el Magnànim, en la seua darrera malaltia (Mur Sancho, 1913, p. 14).

Les autoritats, preocupades pel fet que una vila de la seua categoria no tinguera un "sollemniall metge" i seduïts per la fama de Tresbens, de qui es deia "sie bon metge e gran astròlech", acordaren complaure'l en totes les seues peticions. I, si no hi havia alternativa, acordaren que li pagarien el lloguer de la casa. Això sí, la pensió li la donaven preferentment a 10 anys, i si no hi havia altra opció a 15. Encara, un parell de consellers insistiren en el fet que si Pere d'Isovals podia incorporar-s'hi més aviat, que no continuaren les negociacions amb Tresbens.

El 3 d'octubre es tornaren a reunir. Certament, el contacte amb Tresbens podia resultar molt onerós a l'erari públic, i no tots estaven d'acord amb la seua 
contractació. A més, havien escrit a Pere d’Isovals, que havia respost que si l'esperaven un any es vindria a contractar. La prova que els honoraris sol-licitats eren realment un problema ho és que el consell envià dos dels seus membres a negociar amb Tresbens una reducció del temps de durada del contracte, a un màxim de cinc anys, i una rebaixa del salari.

El 22 d'octubre, reunits de nou, llegiren una carta enviada per un dels síndics desplaçats a Barcelona. La darrera oferta de Tresbens continuava sent inassequible per al Consell de Cervera: 100 florins anuals per un període de 10 anys. Després de reflexionar sobre l'assumpte, s'acordà de contestar-li que li seria donada una pensió de 50 lliures per un període de 10 anys, però hi hagué l'oposició de vuit consellers, que manifestaren que tot plegat era una quantitat molt alta i per un període també massa llarg.

Pel que sembla, les negociacions finalitzaren en aquest punt i el contracte mai no es va materialitzar. Al febrer de 1373, el Consell acordava contractar un franciscà anomenat Guillem Arnau, amb reputació de bon metge, segons afirmaven, per una quantitat de 150 florins anuals, que, com es veu, encara superava la petició de Tresbens, per bé que el contracte degué ser curt, ja que el 1377 ja buscaven un altre físic per contractar (Llobet i Portella, 1990a, p. 117).

Les exigències del metge astròleg havien estat excessives, per molt que la seua fama haguera suposat

\section{NOTES}

1. El MS París, BnF, Esp. 411, inclou el Llibre de les nativitats (f. 1bisr-85r).

2. Es tracta del ms. Ripoll de la Biblioteca Lambert Mata, XXI, col-lecció reunida pel bibliòfil Lambert Mata (Barcelona, 1857-1931). Si Tuixans va consultar directament aquest manuscrit, no ho sabem. Potser per a la seua topografia o per la mera curiositat d'historiador va visitar la biblioteca del monestir i en tingué contacte, o bé, simplement és una més de les seues imprecises notícies.

3. Les fonts sobre les quals es basen aquests treballs han estat analitzades a Giralt, 2017b.

4. En l'actualitat treballe amb Sebastià Giralt en un diplomatari de tota la documentació conservada sobre Bartomeu de Tresbens. Li agraïsc el fet d'haver-me permès consultar els seus treballs inèdits sobre aquest personatge.

5. Arxiu Històric de la Ciutat de Barcelona (AHCB), Estudi, sèrie XVIII, Iligall 9, n. 1. Transcrit i comentat en De la Torre i del Cerro i Rubió i Balaguer, 1971, p. 38-40, doc. 22. un motiu més d'orgull per als prohoms cerverins i una garantia de tenir un bon metge en temps de pesta. Com manifesta Michael McVaugh, en aquestes contractacions individuals es percep una tensió, que motivava la fluctuació de la seua quantia, depenent de si la ciutat o el practicant estaven més o menys ansiosos per omplir la vacant de metge (McVaugh, 1993, p. 199). La voluntat de tenir cobertes les necessitats sanitàries $\mathrm{i}$ de tenir un conseller i metge ben satisfactori hi jugaren un paper determinant. Com s'evidencià en el cas de Cervera, alguns apostaren clarament pel prestigi de l'astròleg reial, mentre que d'altres miraren de salvaguardar els fons municipals i buscar algun metge mestre més econòmic. Tresbens va veure una oportunitat òptima d'assentar-se a Cervera per un llarg període, tot aprofitant la conjuntura pestífera, la por en definitiva, però també la confiança general en la medicina, factors que li van fer pensar que podia esprémer les arques municipals. No va reeixir en la jugada.

\section{AGRAÏMENTS}

Aquest treball s'emmarca en el projecte de recerca "Ciència vernacla a la Corona d'Aragó i al seu context romànic (segles XIII-XVI)" (FFI2014-53050-C5-3-P), finançat pel Ministeri d'Economia i Competitivitat. Vull agrair els encertats comentaris de tota mena dels avaluadors d'aquest treball.

6. En el cas de València, el Consell municipal nomenava anualment dos físics que examinaven aquells que volien dedicar-se a la pràctica mèdica a la ciutat i regne valencians (Rubio Vela, McVaugh i García Ballester, 1989).

7. ACA, Reial Patrimoni (RP), Mestre Racional (MR), n. 345, f. $72 r$ (1362); ACA, RP, MR, n. 482, f. 86r (1363); ACA, RP, MR, n. 491, f. 60r (1368).

8. Al maig de 1386 va cobrar 8 florins, juntament amb el físic Bernat Oriol, per haver-se traslladat de Barcelona a Figueres per atendre el rei. ACA, RP, MR, n. 382, f. 167

9. De la Torre i del Cerro i Rubió i Balaguer, 1971, p. 42. Macià, el seu fill, rebia el 15 de febrer de 1376 una pensió censal de 500 sous barcelonins; la muller, Francesca, rebia el 13 de setembre del mateix any 300 sous de pensió d'un violari. AHCB, Clavaria (XI-11), f. 74v i 197v.

10. Ambdós posseïen esclaus. Ferragud, 2005, p. 124 (Germà). Arxiu Històric de Protocols de Barcelona, Francesc de Montalt, “Capibrevium”, 9-V-1368/19-IX-1368 (4-8-1363) (Tesarac). 
11. ACA, C, reg. 1171, f. 14r (Rubió, 1908-1921, vol. II, p. 131-32).

12. ACA, C, reg. 1619 , f. $171 v-172$ r (14-2-1369); ACA, C, reg. 1713, f. $73 v(18-12-1370)$

13. ACA, C, reg. 1739 , f. 42 v i 43 r.

14. ACA, C, reg. 1739, f. 44r (Rubió, 1908-1921, vol. I, p. 250).

15. ACA, RP, MR, n. 587, f. 52v. La seua estada a Barcelona també està testimoniada el gener de 1373 (ACA, RP, MR, n. 364, f. 109v).

16. ACA, C, reg. 1651 , f. $88 \mathrm{v}-89$ r.

17. ACA, C, reg. 922, f. 75r-v (16-4-1372). Eren freqüents les activitats comercials exercides pels metges més enllà de la seua professió (Ferragud, 2005, p. 435-468).

18. ACA, C, reg. 1742, f. 7v (Rubió, 1908-1921, vol. II, p. 175).

19. ACA, C, reg. 1357, f. 2r. Desplaçament confirmat per un albarà del 8 de desembre (ACA, C, reg. 1357, f. 10v).

20. ACA, C, reg. 1811 , f. $59 \mathrm{v}$ i 60 r

21. ACA, C, reg. 1682 , f. 91v-92v (11-4-1375), i reg. 1625 , f. 189r-v (28-4-1375). Val a dir que Joan I seria especialment incisiu en aquesta política de control de la professió mèdica al llarg del seu regnat, particularment en el cas de dones i minories religioses.

22. Els que s'esmenten en la nota anterior i ACA, C, reg. 1625 , f. 192 r.

23. Cervera va ser un dels primers municipis sensibles a les provisions de les Corts de Montsó de 1289, que regulaven l'accés a la professió mèdica a través de la formació, l'examen i un temps de pràctica. Al maig de 1291, a Cervera s'aplicava aquest procés de control (Duran i Sanpere, 1972, p. 373).

24. ACA, C, reg. 1652, f. 74r-v (8-5-1375). Sobre l'accés als censos i a les explotacions directes de terres per banda dels practicants de la medicina, vegeu Ferragud, 2005, p. 369-434.

25. Els avatars de la contractació han estat exposats anteriorment en Llobet i Portella, 1990a, p. 116-117. Un fragment del document va ser transcrit en Duran i Sanpere i Gómez Gabernet, 1944, p. 5-77 (apèndix doc. 4).

26. Efectivament, els metges podien arribar a acords privats mitjançant un contracte notarial o sense. Aquesta modalitat, en realitat, era bastant més lucrativa. Ens en proporciona un exemple el cas del contracte signat a l'inici del segle XV entre el cirurgià de Barcelona Tristany Sorribes, fincat a Verdú, i uns veïns de Cervera per tal de guarir Pere Ramon "del mal o accident lo qual lo dit Pere Ramon ha en la cuxa e en la anqua". Una actuació que es pactà per 40 florins o 440 sous (Llobet i Portella, 1990b, p. 179-181).
27. L'estudi més complet per al conjunt de la Corona d'Aragó és el de McVaugh, 1993, p. 190-200. Per al cas valencià, vegeu García Ballester, 1988, p. 83-86. Exemples de municipis diversos en Ferragud, 2006a, p. 143-144, i Ferragud, 2006b, p. 99

28. ACA, C, reg. 1227, f. 116 r (13-10-1370).

29. ACA, C, reg. 920 , f. $147 v(2-5-1371)$.

30. ACA, C, reg. 1683 , f. 154 r (10-1-1379).

31. També a Vilafranca del Penedès la política de Pere el Cerimoniós fou molt semblant, concedint autoritzacions per a practicar la medicina (Ferragud, 2013-2014, p. 20).

32. ACA, C, reg. 906 , f. 26 r (29-8-1361) i reg. 1678 , f. $12 v$ (13-6-1369). Al desembre de 1369 cobrava 450 sous per la venda de confits de sucre per a la casa reial. ACA, RP, $M R$, n. 358, f. 157r.

33. ACA, C, reg. 1757, f. $30 v-31 r(1-7-1385)$.

34. Sobre la prohibició de les aliances metge-apotecari en les lleis, vegeu, per al cas valencià, Rubio-Vela, McVaugh i García-Ballester, 1989, p. 6-7 i apèndix 2. Casos semblants a Castella en García Ballester, 2000, p. 581-582.

35. ACA, C, reg. 1246, f. 54v-55r (20-12-1374). També el rei intervindria nomenant un jutge en l'apel·lació a una sentència en contra de Bartomeu en un plet $\mathrm{amb}$ un altre veí de Cervera. ACA, C, reg. 761, f. 107r (6-9-1372).

36. ACA, C, reg. 1253 , f. $126 r(28-4-1376)$.

37. ACA, C, reg. 795, f. 86v-87r (1-3-1378).

38. ACA, C, reg. 797, f. 51v-52r (8-3-1378).

39. ACA, C, reg. 797, f. 100r-v (23-3-1378).

40. ACA, C, reg. 1452, f. 20v-22r (9-8-1378). ACA, C, reg. 802, f. 123r-v (3-11-1378); f. 137r-v (16-11-1378); f. 155r (30-111378). ACA, C, reg. 801, f. 81v-82r (15-11-1378).

41. ACA, C, reg. 807, f. 188v-189r (8-9-1379).

42. ACA, C, reg. 815, f. 46v-47r (28-9-1381)

43. ACA, C, reg. 756, f. 86r (10-3-1371).

44. En alguns contractes valencians que hem explorat, els metges solen obligar-se a atendre de franc els veïns només dues vegades l'any. La resta d'ocasions el tractament corria a càrrec del pacient. Vegeu, per exemple, el cas del físic Domingo de Navarrete, contractat a Vila-real (Regne de València) I'1 d'octubre de 1427: "ajudar de sa art de medecina a totes aquelles persones de la dita vila que mester e necessari fos, ço és, fins en una o dues vesitacions francament e sens ninguna remuneració, e de ajudar e obrar en los pacients tant quan sa posibilitat fos e Déu li endreçaria". Arxiu Municipal de Vila-real, Manual de Consells, 13, f. 11v. 


\section{BIBLIOGRAFIA}

Benito i Monclús, Pere (1999), “Documentació medieval sobre Cervera, dins la col·lecció Joan Gili, conservada a la Houghton Library, Harvard University", Miscel/lània Cerverina, 13, pp. 215-223.

Black, Robert (2004), "École et société à Florence aux XIVe et $\mathrm{XV}^{\mathrm{e}}$ siècles. Le témoignage des ricordanze", Annales HSS, 59 (4), pp. 827-846.

Black, Robert (2005), "Education and the emergence of a literate society". En: Najemy, John M. (ed.), Short Oxford history of Italy: Italy in theage of Renaissance, 1300-1550, Oxford, Oxford University Press, p. 18-36.

Canela i Garayoa, Montserrat (1986), “Cervera 1333-1384. Pestes, fams i guerres", Miscel/lània Cerverina, 4, pp. 55-66.

Carreras Artau, Joaquín; Batllori, Miquel (1947), "La patria y la familia de Arnau de Vilanova, a propósito de un libro reciente", Analecta Sacra Tarraconensia, 20, pp. 5-71.

Chabàs, Josep (2004), "L'activitat astronòmica a l'època del rei Pere (segle XIV)". En: Vernet, Joan; Parés, Ramón (eds.), La ciència en la història dels Països Catalans, València, Publicacions de la Universitat de València, vol. 1, pp. 483-514.

Cifuentes, Lluís (1995), Medicina i guerra a l'Europa baix-medieval: la sanitat i la participació dels seus professionals en les expedicions militars de la Corona d'Aragó (1309-1355), Tesi doctoral, Universitat Autònoma de Barcelona.

Cifuentes, Lluís (2006), La ciència en català a l'Edat Mitjana i el Renaixement ( $2 \mathrm{a}$ ed.), Barcelona-Palma, Universitat de Barcelona-Universitat de les Illes Balears.

Comenge, Lluís (1901), "El protofísico de Pedro el Cerimonioso", Real Academia de Buenas Letras, I, pp. 151-157.

Cruselles, José María (1997), Escuela y sociedad en la Valencia bajomedieval, València, Diputació de València.

Duran i Sanpere, Agustín; Gómez Gabernet, Frederic (1944), "Las Escuelas de Gramática en Cervera", Boletín de la Real Academia de Buenas Letras de Barcelona, 17, pp. 5-77.

Duran i Sanpere, Agustín (1972), Llibre de Cervera, Tàrrega, F. Camps Calbet.

Ferragud, Carmel (2005), Medicina i promoció social a la Baixa Edat Mitjana (Corona d'Aragó, 1350-1410), Madrid, CSIC.

Ferragud, Carmel (2006a), "La salut i l'assistència mèdica dels camperols i dels seus animals al País Valencià durant la Baixa Edat Mitjana". En: Bolòs, Jordi; Jarné, Antonieta; Vicedo, Enric (eds.), Condicions de vida al món rural: cinquè congrés sobre sistemes agraris, organització social i poder local, Lleida, Institut d’Estudis Ilerdencs, pp. 131-150.

Ferragud, Carmel (2006b), "Medicina i societat a Alzira durant la Baixa Edat Mitjana", En: Riuades $i$ inudacions a la Ribe- ra del Xúquer en la perspectiva històrica - Actes de la X Assemblea d'Història de la Ribera. Volum Miscel-lani (Antella, novembre 2004), Antella, Ajuntament d'Antella, pp. 89-102.

Ferragud, Carmel (2013-2014), "La médecine en milieu rural dans la Couronne d'Aragon au Moyen Âge", Etudes RoussiIlonnaises, 26, p. 15-22.

Ferragud, Carmel; López Terrada, Marialuz (2017), “El culte al document: I'historiador valencià Josep Rodrigo Pertegàs", Afers, 86, pp. 119-145.

Ferrer i Mallol, Maria T. (2001), "Fruita seca i assecada, una especialitat de l'àrea econòmica catalana-valenciana-balear", Anuario de Estudios Medievales, 31 (2), pp. 883-943.

García Ballester, Lluís (1988), La medicina a la València medieval. Medicina i societat en un país medieval mediterrani, València, Alfons el Magnànim.

García Ballester, Luis (2000), La búsqueda de la salud. Sanadores y enfermos en la España medieval, Barcelona, Península.

Giralt, Sebastià (2017a), "Astrology in the Service of the Crown: Bartomeu de Tresbens, Physician and Astrologer to King Pere the Ceremonious of Aragon", Journal of Medieval History, 44 (1), pp. 104-129, https://doi.org/10.1080/0304418 1.2017.1397534

Giralt, Sebastià (2017b), "Drawing from the marrow of the authors of astrology: the sources of Bartomeu de Tresbens, astrologer to king Pere the Ceremonious of Aragon", En: Boudet, Jean-Patrice; Ostorero, Martine; Paravicini-Bagliani, Agostino (eds.), De Frédéric II à Rodolphe II. Astrologie, divination et magie dans le cours (XIIle-XVIle siècle) (Micrologus Library, 85), Florència, SISMEL-Edizioni del Galluzzo, pp. 71-96.

Llobet i Portella, Josep M. (1983), "Les epidèmies a Cervera durant I’Edat Mitjana”, Miscel/lània Cerverina, 1, pp. 39-46.

Llobet i Portella, Josep M. (1990a), "Els metges a Cervera durant els segles XIV i XV”, Gimbernat, 13, pp. 115-140.

Llobet i Portella, Josep M. (1990b), “Una cura pactada entre el cirurgià Sorribes i la família Ramon (1404)", Gimbernat, 14, pp. 179-181.

Llobet i Portella, Josep Maria (1999), "Les escoles de Cervera segons els capítols per al seu regiment (1445-1693)", Palestra Universitària, 11, pp. 49-136.

McVaugh, Michael R. (1993), Medicine before the plague: practitioners and their patients in the Crown of Aragon, 1285-1345, Cambridge, Cambridge University Press.

Mur Sancho, Jaime (1913), Recuerdo apologético de Gabriel García, maestro en medicina, archiatro de los reyes de Aragón, València, Tipografía Moderna. 
Pujol i Ros, Joan (2012), La topografia mèdica de Montserrat del Dr. Joaquim Tuixans i Pedragosa (c. 1905), Manresa, Arxiu Històric de les Ciències de la Salut.

Rubió i Lluch, Antoni (1908-1921), Documents per I'historia de la cultura catalana mig-eval, Barcelona.

Rubio-Vela, Agustín; McVaugh, Michael R.; García Ballester, Luis (1989), "Medical licensing and learning in fourteenth century Valencia", Transactions of the American Philosophical Society, 79 (6), pp. 1-128.

Ryan, Michael R. (2011), A Kingdom of Stargazers: Astrology and Authority in the Late Medieval Crown of Aragon, Ithaca (NY), Cornell University Press.

Solsona, Francina; Sorní, Xavier (1984), “Un apotecari de Cervera amb permís per a exercir la medicina", Miscel-lània Cerverina, 2 , pp. 43-48.

Torre y del Cerro, Antonio de la; Rubió i Balaguer, Jordi (1971), Documentos para la historia de la Universidad de Barcelona. I. Preliminares (1289-1451). Introducció, notes i comentaris de Jordi Rubió Balaguer, Barcelona, Universitat de Barcelona.
Tresbens, Bartomeu de (1957-1958), Tractat d'astrologia, Vernet, Joan; Romano, David (eds.), Barcelona, Biblioteca Catalana d'Obres Antigues.

Tuixans, Joaquín. (1926), Noticiario de la familia de mestre Arnau de Vilanova, metge valencià: segle XIII, Vila-real, Impr. de Juan A. Botella.

Turull, Max (1989), Oligarquia, fiscalitat i règim municipal al món urbà de la Catalunya medieval (Cervera entre $1026 i$ 1430), Tesi doctoral, Universitat de Barcelona.

Turull, Max (1990), La configuració jurídica del municipi Baix-Medieval, Barcelona, Fundació Noguera.

Turull, Max (1992), "Agricultura i ramaderia a Cervera als segles XIII i XIV", Miscel/lània Cerverina, 8, pp. 65-96.

Vela i Aulesa, Carles (2015), "Defining 'Apothecary' in the Mediaeval Crown of Aragon". En: Flocel, Sabaté (ed.), Medieval Urban Identity: Health, Economy and Regulation, Cambridge, Cambridge Scholars Publishing, pp. 127-142.

Verger, Jacques, dir. (1999), “Éducations Médiévales, L’enfance, l'école, l'église en Occident Ve-XVe siècles", Histoire de l'Education, 50. 